Portland State University

PDXScholar

\title{
Better Futures: a Randomized Field Test of a Model for Supporting Young People in Foster Care with Mental Health Challenges to Participate in Higher Education
}

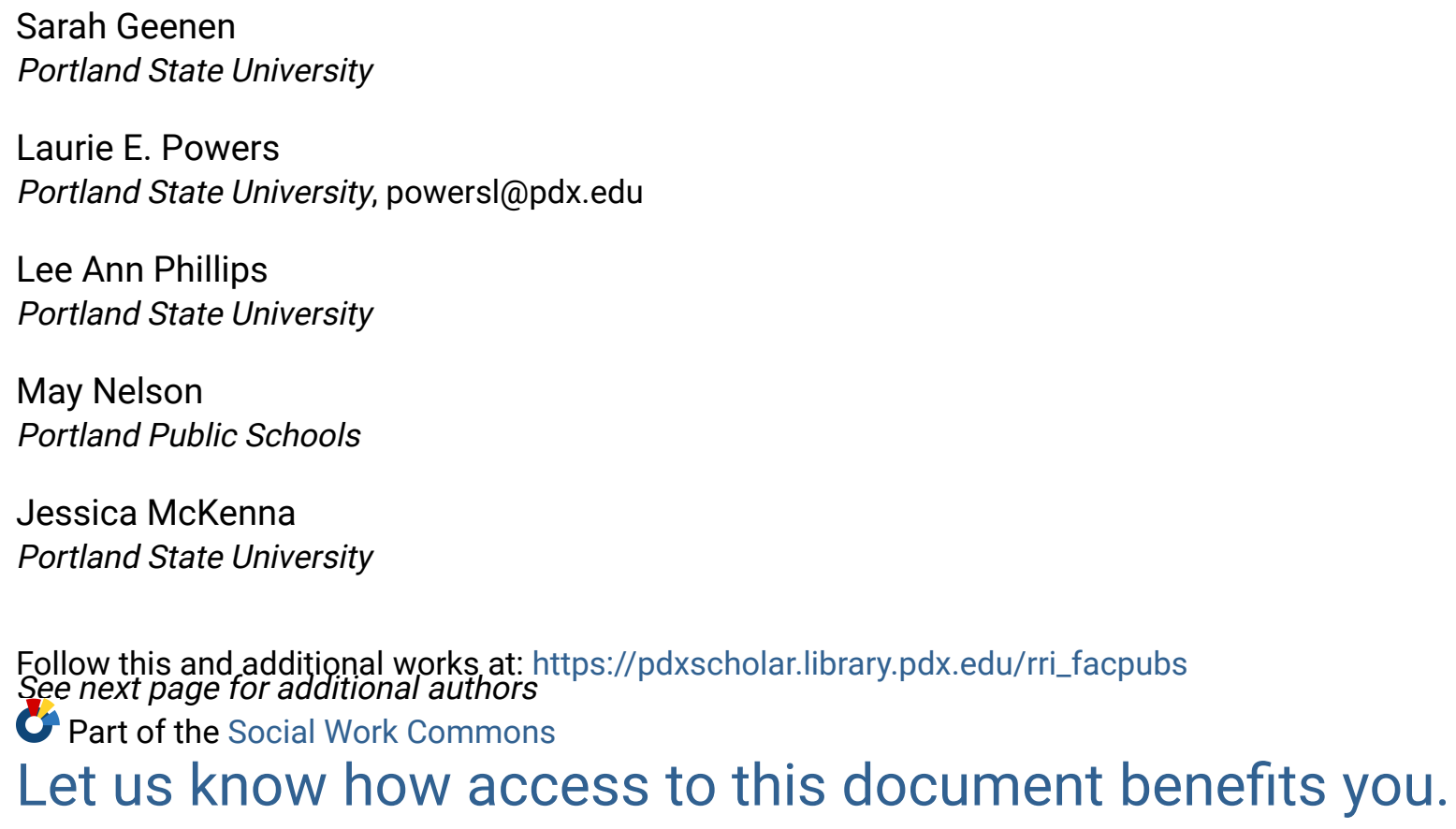

Sarah Geenen

Portland State University

Laurie E. Powers

Portland State University, powersl@pdx.edu

Lee Ann Phillips

Portland State University

May Nelson

Portland Public Schools

Jessica McKenna

Portland State University

Follow this and additional works at: https://pdxscholar.library.pdx.edu/rri_facpubs See next page for additional authors

Part of the Social Work Commons

Let us know how access to this document benefits you.

Citation Details

Published as: Geenen, S., Powers, L.E., Phillips, L.A. et al. J Behav Health Serv Res (2015) 42: 150.

This Post-Print is brought to you for free and open access. It has been accepted for inclusion in Regional Research Institute by an authorized administrator of PDXScholar. Please contact us if we can make this document more accessible: pdxscholar@pdx.edu. 


\section{Authors}

Sarah Geenen, Laurie E. Powers, Lee Ann Phillips, May Nelson, Jessica McKenna, Nichole Winges-Yanez, Linda Blanchette, Adrienne Croskey, Lawrence D. Dalton, Amy Salazar, and Paul Swank 
[This manuscript was published online December 12, 2014 in the

Journal of Behavioral Health Services \& Research. The final publication is available at

Springer via http://link.springer.com/article/10.1007/s11414-014-9451-6]

\title{
Better Futures: a Randomized Field Test of a Model for Supporting Young People in Foster Care with Mental Health Challenges to Participate in Higher Education
}

Sarah Geenen, Laurie E. Powers, Lee Ann Phillips, Jessica McKenna, Nichole Winges-Yanez, Adrienne Croskey, May Nelson, Linda Blanchette, Lawrence D. Dalton, Amy Salazar, \& Paul Swank.

\begin{abstract}
The purpose of the study was to conduct a preliminary efficacy evaluation of the Better Futures model, which is focused on improving the postsecondary preparation and participation of youth in foster care with mental health challenges. Sixty-seven youth were randomized to either a control group that received typical services or an intervention group, which involved participation in a Summer Institute, individual peer coaching, and mentoring workshops. Findings indicate significant gains for the intervention group on measures of postsecondary participation, postsecondary and transition preparation, hope, self-determination, and mental health empowerment, as compared to the control group. Youth in the intervention group also showed positive trends in the areas of mental health recovery, quality of life, and high school completion. Implications for future research and practice are discussed, while emphasizing the capacities of youth in foster care with mental health conditions to successfully prepare for and participate fully in high education.
\end{abstract}

\section{Introduction}

While nationally the total number of children and youth in foster care has modestly declined during the past decade, the percentage of youth exiting care through emancipation has steadily increased, with $10 \%$ or 23,396 youth aging-out of foster care in 2012. ${ }^{1}$ Research findings consistently underscore poor outcomes for youth and young adults emancipating from foster care. ${ }^{2-6}$ Midwest Evaluation Study follow-along findings from 596 former foster youth, 25-27 years of age, highlight the persistence of these problems, with an employment rate of $48.3 \%$ vs $79.9 \%$ for young adults in the general population; median annual earnings $\$ 18,000$ below those of young adults in the general population; and incarceration rates that are ten times greater than those of young adults in the general population. ${ }^{3}$

To complicate matters, many youth exiting foster care experience mental health challenges, often in association with exposure to trauma, separation from bio family, placement changes, and other stressors, which are unfortunately typical for many youth in care. The Northwest Foster Care Alumni study found that among young adults who had recently exited the foster care system, $54 \%$ had a diagnosed mental health problem, with $25 \%$ experiencing PTSD and 20\% experiencing major depression. ${ }^{6}$ Courtney $^{3}$ reported the following levels of mental health symptomology among Midwest evaluation 
study participants: $33 \%$ social anxiety, 25\% depression, and 60\% PTSD, with $14.5 \%$ taking psychotropic medications. Anctil ${ }^{7}$ also found that foster youth with serious mental health conditions had poorer physical health and lower self-esteem than former foster youth without mental health challenges.

\section{Unrealized Benefits of Postsecondary Education}

Postsecondary education is an influential factor in adult success, overall and in particular for disadvantaged youth. ${ }^{8}$ Postsecondary education is associated with increased earning potential, ${ }^{9}$ enhanced health status, reductions in risk behaviors such as delinquency and smoking, and increased community participation. ${ }^{10}$ For many young people with compounded disadvantages of having serious mental health conditions and living in foster care, enrolling in a satisfying post-secondary program could signal a major turning point toward increased autonomy, community integration, productivity, and quality of life. ${ }^{11-13}$

Although the overwhelming majority of youth in foster care (70-80\%) want to go to college or vocational school, ${ }^{14-16}$ many do not have the opportunity. ${ }^{17}$ Courtney and Dworsky ${ }^{2}$ found that $39 \%$ of former foster youth were enrolled in higher education at 19 years of age, compared to $59 \%$ of youth in the general population. At 21 years of age, only $25 \%$ of former foster youth were in postsecondary education, compared to $44 \%$ of young adults in the general population. ${ }^{18}$ For those foster youth who successfully completed high school, McMillen and collegues ${ }^{15}$ found that only $20 \%$ went on to college, in contrast to $60 \%$ in the general population. This disadvantage continues during early adulthood, with only eight percent of former foster youth, 2527 years of age, reporting that they graduated with two- or four-year postsecondary degrees, compared to a $46 \%$ graduation rate for young adults in the general population. ${ }^{3}$ Almost $80 \%$ of these former foster youth said they needed additional education to achieve their career goals. ${ }^{3}$

The statistics are similarly disappointing for young people with mental health conditions. For example, a follow-along study of youth with mental health issues in high school found that over $80 \%$ expected to participate in higher education. ${ }^{19}$ However, four years after high school, only $34 \%$ had actually participated. ${ }^{20}$ Information is not available that documents the postsecondary participation rates of youth in foster care with serious mental health conditions; however, these young people most likely experience compounded disadvantages.

\section{Barriers to Accessing Postsecondary Education}

Young adults exiting the foster care system face numerous challenges that impede their pursuit of higher education; barriers such as low high school achievement, premature transition to independence, lack of family and other adult support, low expectations for success, housing insecurity, high rates of single parenthood, pressure to work fulltime to manage poverty, lack of transportation, and incarceration. ${ }^{3,14,21-24}$

Lower rates of high school completion are associated with decreased rates of postsecondary enrollment, retention, and completion among young adults exiting foster care. ${ }^{2}$ In reviewing a series of studies, Wolanin ${ }^{24}$ found an on-time high school graduation rate of $50 \%$ for foster youth, compared to about $70 \%$ for youth overall. Six to eight years post high school, Courtney ${ }^{3}$ found that $20 \%$ of former foster youth still did not have a high school diploma or a GED, compared to $6 \%$ in the general population. Likewise, youth with serious mental health conditions have the lowest high school completion rate of all youth with disabilities at 56\%. ${ }^{19}$ Geenen and Powers ${ }^{25}$ found that youth in foster care with disabilities in high school (including emotional and behavioral disabilities) have lower grades, change schools more frequently, and earn fewer credits towards graduation than youth in foster care without disabilities. Further, Smithgall ${ }^{26}$ found that only $16 \%$ of foster youth with a primary special education classification of emotional disturbance graduated from high school. Schools commonly respond to youths' absenteeism, poor performance, and behavioral problems - often related to trauma history and life instability - with suspension, expulsion, and restrictive educational placements. ${ }^{27}$ These $\mathrm{pu}-$ nitive measures further isolate youth from educational opportunities and supports, and restrict their 
hopes and capacities for pursuing postsecondary education.

In addition to lacking foundational academic preparation and support, many youth in foster care do not have consistent adults that encourage them in school or advocate for them..$^{28,29}$ Foster youth often receive insufficient support from families and others to complete the myriad of tasks required to succeed in college. ${ }^{30}$ Interviews with 20 young adults emancipating from care suggest particular gaps in instrumental and appraisal support, including assistance in carrying out activities required to establish an independent life and someone to offer confidence, hope, and encouragement. ${ }^{31}$

Low expectations of school staff, child welfare, mental health, and other professionals, as well as increased likelihood of living in restrictive foster care placements, further limit opportunities for youth in care with mental health issues to learn about and prepare for higher education..$^{29,32}$ While many youth in foster care with mental health issues retain their dreams of going to college, they may not receive services that could promote their success. For example, the earliest and only comparison study of services for youth in foster care with various disabilities revealed that youth who had an emotional disability were less likely to receive services, including help with applying to college, compared to youth in foster care with other types of disabilities and without disabilities. ${ }^{33}$ Subsequent findings confirm that youth with serious mental health conditions in foster care access fewer supports to prepare and apply for postsecondary programs. ${ }^{34}$ These barriers leave many youth disconnected from educational opportunities and supports, and questioning whether higher education could be possible.

Young people with serious mental health conditions in foster care also may be reluctant to disclose their mental health and foster care statuses due to concerns about being singled out for special treatment that exacerbates feeling "different" and fear of other's low expectations, stigma and discrimination. ${ }^{35}$ Further, adult mental health services are limited and often unwelcoming to youth. ${ }^{36}$ With regard to disclosure in postsecondary programs, Newman ${ }^{20}$ and colleagues found that approximately
$21 \%$ of students disclosed their mental health conditions. Yet, disclosure of foster care experience can open doors to additional financial assistance and other supports, and disclosure of disability status is required to receive postsecondary accommodations.

Although some progress has been achieved in postsecondary participation by youth in foster care, ${ }^{37}$ these multiple and persistent barriers underlie the still dismal level of postsecondary preparation of young people emancipating from foster care, especially those with serious mental health issues. Major legislation has been adopted to offer increased support to young people emancipating from foster care, including: (a) The John H. Chafee Foster Care Independence Program, which increased funding for states to provide foster care independent living services, ${ }^{38}$ and which through amendments provides Education and Training Voucher Program funds to off-set the cost of college, ${ }^{30}$ and requires follow-up data be collected on the outcomes of emancipating foster youth; (b) The 2008 Fostering Connections Act, which requires that youth preparing to exit foster care have a written transition plan; and (c) The 2013 Uninterrupted Scholars Act, which amended FERPA to enable exchange of educational information between schools and child welfare. Increasing resources also are being directed toward promoting the postsecondary success of youth exiting foster care, including additional state-level postsecondary tuition assistance and campus support programs, such as Guardian Scholars and Renaissance Scholars. ${ }^{22}$ However, intervention approaches with proven efficacy for supporting young people in foster care with mental health challenges to successfully enter the postsecondary education gateway are virtually nonexistent and urgently needed.

\section{Better Futures Project}

The Better Futures Project developed and tested a model to empower and support young people in foster care with serious mental health challenges to prepare for and enter postsecondary education. ${ }^{39}$ The Better Futures model is an adaptation of the My Life intervention, which includes individualized coaching for youth around key self-determination 
skills while working to achieve their personally identified goals and mentoring workshops with near peers who have shared experience around foster care. ${ }^{40}$ The model is informed by best practices in youth-centered postsecondary planning,; ${ }^{41}$ selfdetermination enhancement; ${ }^{40,42}$ and peer support in mental health. ${ }^{43,44} \mathrm{~A}$ centerpiece of the model is support provided to youth by near-peers who are in college themselves and who have shared experiences around foster care and/or mental health. Described in this article, a preliminary efficacy evaluation of the Better Futures model was conducted through a randomized, longitudinal study involving 67 youth in foster care with mental health issues. Outcomes examined included high school completion, postsecondary participation, self-determination, mental health, quality of life, hope, and postsecondary and transition planning. Two major research questions investigated whether youth who participated in the Better Futures model showed significant improvement on these outcomes and, most important for judging effectiveness, whether the outcomes of youth who participated in Better Futures were significantly improved, as compared to the outcomes of youth randomized to a community as usual control group.

\section{Method}

The outcomes of the intervention were evaluated with a two-independent groups ${ }^{\star}$ four repeated measures design. Sixty-seven youth (36 intervention, 31 control) were enrolled over three study waves. Following informed assent/consent and baseline assessment, youth were randomly assigned to either the intervention or control group. A slightly larger number of youth were randomized to the intervention group to provide the team with additional experience in delivering the intervention. Youth participating in the control group received typical services (community as usual), including supports available to all youth (e.g. a guidance counselor at school) and specific to youth in foster care (e.g., Independent Living Program) and youth with mental health conditions (e.g., therapy).

\section{Participants}

Youth eligible to participate in the Better Futures Project were (a) in the guardianship of the state foster care system; (b) living within the project's geographic area; (c) in high school or a GED program and one or two years away from completion of secondary education; and (d) identified as experiencing a significant mental health condition, defined by receiving special education services for an emotional disability, taking psychotropic medication, living in therapeutic settings (such as treatment foster care), or receiving mental health counseling. In addition, youth had to say they were not opposed to the idea of exploring college or vocational school, and they had not yet applied.

To identify youth for the study, the state foster care program generated a list of all youth who were in foster care within the project's target area and in the approximate age range for high school. This list was then cross-referenced with school district data to confirm a youth's grade level and special education status in the emotional and behavioral category. Information was also collected from the state foster care program's database regarding a youth's placement type (e.g. therapeutic foster care), mental health services, prescribed medications, and confirmed DSM-IV diagnoses. If information gathered from these databases indicated a youth experienced a mental health condition, with the case worker's approval, a DHS liaison made initial contact with potential participants to ask if they were interested in meeting with project staff to learn more about the project; in all instances youth were interested in learning more about the project and a follow-up orientation meeting was set-up with each youth, their caregiver (typically a foster parent), and the project manager. During this time, the project was described in more detail, and the youth's eligibility was confirmed. The only other criteria for excluding youth from the study was placement in a locked facility that would not permit a youth to leave with a project staff member to participate in project activities. Approximately $87 \%$ of youth invited to enroll in the project decided to join and gave their assent; as legal guardian, the state foster care agency provided consent for youth who chose to participate. 
The recruitment and enrollment procedures were approved by Portland State University's IRB and Oregon DHS's Child Welfare Data and Research Committee.

\section{Intervention Overview}

Intervention group youth participated in three interrelated components over approximately 10 months: (1) a four day, three night Summer Institute on a university campus; (2) individual, bimonthly peer coaching; and (3) four mentoring workshops. Each of the intervention components is summarized below and more detailed information is available from Phillips. ${ }^{45}$

Summer Institute. Youth lived in the dorms and participated in a variety of experiences, including informational sessions, tours of both the university and a nearby community college campus, and facilitated discussions of higher education preparation, mental health, accommodation needs, and transition resources, with near peers who had lived experience with foster care and mental health, high school and college or vocational education representatives and other professionals. Evening social activities more informally connected youth and near peers. The Summer Institute was facilitated by peer coaches, other project staff and two young adults from FosterClub, a national leadership group for young people in foster care.

Peer coaching. Peer coaching was provided by young adults (under the age of 28), who were in higher education and had shared experiences around foster care and/or mental health challenges. Peer coaches were recruited from the university and community college, and they received about 40 hours of initial training in a variety of areas, including foster care, mental health, secondary education, and postsecondary issues, support strategies, and resources related to accessing higher education, self-determination promotion, strategic self-disclosure, and intervention and fidelity protocols. Coaches participated in weekly individual and group supervision meetings facilitated by the intervention manager.

Commencing just prior to the Summer Institute, individualized one-on-one peer coaching was provided to youth approximately twice a month for nine months, and was focused on supporting youth in working toward their goals and managing barriers. Youth were supported to identify postsecondary goals, and strategies and supports to reach goals; to share their goals with others and enlist support; to problem-solve solutions to barriers; to carry out activities needed to achieve goals; and to identify and apply strategies for self-care and wellness. Exposure to 11 targeted experiential activities and 11 self-determination skills was specified in the intervention protocol (e.g., visit a college or vocational program, review high school transcript, practice in negotiation and problem-solving). Peer coaches met with youth in their schools, neighborhoods, and other convenient places.

Mentoring workshops. Five workshops were organized for each cohort by peer coaches and other project staff. Youth were asked to attend at least four of the workshops, in an effort to provide them with some scheduling flexibility. Mentoring workshops brought together youth and their coaches for discussions and experiences that were guided by speakers with expertise around child welfare, mental health and higher education. Youth selected the topics for the workshops, which typically included an overview of the college application process, review of the senior timeline for college application activities, mental health and self-care, and transition services and resources. All of the workshops included foster care alumni and/or professionals who presented information on a given workshop topic and facilitated youth in an activity (e.g., Scholarship and College Admission with an essay writing activity), as well as providing opportunities for informal networking during a fun activity (e.g. food and bowling).

Intervention fidelity. For the Summer Institute, participation of youth in ten different sessions was tracked on the fidelity checklist; $100 \%$ fidelity was achieved. With regard to peer coaching, youth and coaches spent an average of 9.31 hours in experiential activities, 10.92 hours in relational time, and 7.13 hours in didactic learning. Overall, coaches spent an average of 27.37 hours per wave with youth, meeting an average of 15 times. Fidelity 
across the three waves was $99.5 \%$ for targeted selfdetermination skills, and $89.7 \%$ for targeted experiential activities, and participants attended an average of 3.47 workshops.

\section{Measurement}

Measures. Instruments were selected because they provided strong face validity and were optimal measure of a key construct or outcome area, they had been used previously with a similar population (e.g. young people in foster care, young people with mental health conditions or other disabilities) and they had established psychometric properties. On central constructs/outcome areas (self determination, mental health, postsecondary planning) multiple measures were used to enhance construct validity (e.g. examining whether different measures evaluating the same construct behave similarly) and minimize measurement error; total scores were used for each measure and were administered to assess the following concepts: (a) Demographics (e.g., age, sex); (b) Educational, employment, and living status; (c) Self-determination (Arc Self Determination Scale; ${ }^{46}$ and AIR Self-Determination Scale ${ }^{47}$ ); (d) Mental health (Youth Empowerment Scale-Mental Health; ${ }^{48}$ youth-tailored version of Mental Health Recovery Measure; ${ }^{49}$ and Youth Self-Report; ${ }^{50}$ (e) Quality of life (Quality of Life Questionnaire, ${ }^{51}$ (f) Hope (Hopelessness Scale for Children, ${ }^{52}$ revised from a dichotomous true/false scale to a Likert 4 point scale); and (g) Postsecondary and transition planning (Career Decision Self-Efficacy Scale, ${ }^{53}$ Assessing Barriers to Education; ${ }^{54}$ Transition Planning Assessment. ${ }^{40}$ Additionally, a postsecondary preparation questionnaire, successfully used in a previous study of the educational outcomes of selfdetermination enhancement ${ }^{52}$ was expanded to include 24 key activities associated with preparing for and applying to college (e.g. completing FAFSA, touring a college campus, submitting a college application, etc.). A higher score from T1 to T4 signifies improvement over time for all measures except Assessing Barriers to Education, ${ }^{54}$ and the Hopelessness Scale. ${ }^{52}$ For those two measures, a higher score over time indicates an increase in barriers or hopelessness.
Data Collection. Following assent/consent, each youth completed baseline assessment and was randomized to study group. Youth subsequently completed assessments three more times: after the Summer Institute (approximately one month post enrollment); following conclusion of the intervention (ten months after enrollment); and after a six-month post-intervention follow-along period (16 months after enrollment). Youth were paid a stipend (\$30) after each assessment to thank them for their time. Information about the foster care experiences of youth (e.g., placement change) was gathered from the state's child welfare electronic database, and school data (e.g. grade, special education eligibility) was obtained from the school district's electronic database and copies of student transcripts, information about receipt of developmental disability services was obtained from the county program providing those services, and the remaining information (e.g. age, ethnicity, medication, mental health services) was gathered through youth self-report.

\section{Results}

A total of 67 youth were enrolled in the study, assessed at baseline and randomized (36 intervention, 31 control). At Time 2 (approximately one month after baseline, immediately following the Summer Institute), all but one youth were assessed; a youth randomized to the intervention group could not be located for the Summer Institute and was lost to the study. At Time 3 (ten months after baseline, following intervention completion) 60 youth were assessed (33 intervention, 27 control) and at Time 4 (approximately 16 months after baseline, end of 6 month follow along) 59 youth (34 intervention and 25 control) could be reached for assessment. One intervention youth that was missing at Time 3 was located for the T4 assessment, while two additional control group youth were lost from T3 to T4. Thus, the overall attrition rate from $\mathrm{T} 1$ to $\mathrm{T} 4$ was approximately $9 \%$.

\section{Sample Characteristics}

The demographic characteristics of the sample are shown in Table $1(n=67)$. At enrollment, 
Table 1. Demographic characteristics of Better Futures study participants

\begin{tabular}{|c|c|c|c|}
\hline Characteristic & Control $(n=31)$ & Intervention $(n=36)$ & Total $(n=67)$ \\
\hline Age (Mean) & 16.74 & 16.78 & 16.76 \\
\hline Gender ( $\%$ Female) & 51.6 & 52.8 & 52.2 \\
\hline \multicolumn{4}{|l|}{ Race/ethnicity (\%) } \\
\hline Hispanic & 3.2 & 5.6 & 4.5 \\
\hline Native American & 32.3 & 16.7 & 23.9 \\
\hline Asian & 0 & 2.8 & 1.5 \\
\hline African American & 16.1 & 22.2 & 19.4 \\
\hline Caucasian & 38.7 & 44.4 & 41.7 \\
\hline Multi-ethnic & 9.7 & 8.3 & 9.0 \\
\hline \multicolumn{4}{|l|}{ Placement type \% } \\
\hline Non-relative Foster Care & 64.5 & 63.9 & 64.2 \\
\hline Relative Foster Care (Kinship) & 25.8 & 27.7 & 26.8 \\
\hline Group home/Residential Treatment & 6.5 & 8.3 & 7.5 \\
\hline Other (with a friend/own apartment) & 3.2 & 0 & 1.5 \\
\hline Length of time in foster care (mean years) & 6.9 & 5.6 & 6.2 \\
\hline Experienced placement change in past year \% & 48.4 & 30.6 & 38.8 \\
\hline Total number of placement moves past year & 2.73 & 2.82 & 2.77 \\
\hline \multicolumn{4}{|l|}{ Reason for entering foster care (\% non-exclusive) } \\
\hline Physical & 48.4 & 54.3 & 51.5 \\
\hline Sexual & 12.9 & 25.7 & 19.7 \\
\hline Neglect & 67.7 & 68.5 & 68.2 \\
\hline Threat of Harm & 29.0 & 42.8 & 36.4 \\
\hline Parental Substance Abuse & 38.7 & 31.4 & 34.8 \\
\hline Parent Not Able to Cope & 29.0 & 14.2 & 21.2 \\
\hline Other & 3.2 & 28.6 & 15.2 \\
\hline \multicolumn{4}{|l|}{ School Status } \\
\hline Working towards GED \% & 16.2 & 8.3 & 12.0 \\
\hline Attending school \% & 83.3 & 91.7 & 88.0 \\
\hline \multicolumn{4}{|l|}{ Grade } \\
\hline Sophomore & 3.8 & 3.0 & 3.4 \\
\hline Junior & 50.0 & 36.4 & 42.4 \\
\hline Senior & 46.2 & 60.6 & 54.2 \\
\hline Taking mental health medication $\%$ & 29.0 & 48.6 & 39.4 \\
\hline Receiving mental health services \% & 64.5 & 72.2 & 68.7 \\
\hline Receiving special education services \% & 41.9 & 30.5 & 35.8 \\
\hline Receiving developmental disability services \% & 12.9 & 8.3 & 10.4 \\
\hline
\end{tabular}

Better Futures: a Randomized Field Test of a Model for Supporting Young People... 
participants ranged from 16 to 18 years of age $(M=$ $16.76, \mathrm{SD}=.62$ ), with females accounting for slightly more than half the sample $(52.2 \%)$. More than half were young people of color; $23.9 \%$ identified themselves as Native American, 19.4\% were African American, 9\% were multi-racial, 4.5\% were Hispanic, $1.5 \%$ were Asian and the remaining $41.7 \%$ were Caucasian. Almost $70 \%$ of youth were receiving mental health services and 39\% were taking mental health medication. Approximately one-third of participants were receiving special education services and just over 10\% were receiving Developmental Disability Services. While control and intervention youth varied slightly on a number of characteristics (e.g. medication, special education, school status) none of these group differences were statistically significant.

\section{Education, Employment, and Living Status}

Educational achievement. Eighty-eight percent of participants were attending high school at study enrollment; the remaining $12 \%$ were working on their GED. Among participants attending high school, $60.6 \%$ of youth randomized to the intervention were seniors as compared to $46.2 \%$ of control youth; this group difference was not statistically significant. At the end of follow along period (T4), $52 \%$ of control youth had completed high school (graduation or GED), 36\% were still attending HS, and $12 \%$ had dropped out. In contrast, $65 \%$ of intervention group youth had graduated high school, $29 \%$ are still attending HS, and 6\% had dropped out.

No youth in either group were participating in postsecondary education at baseline. At the conclusion of follow along (T4), 65\% of intervention and $24 \%$ of control youth were participating in higher education; a significant difference between groups $\left[\chi^{2}=9.57, d f=1, p<.001\right]$. Among intervention youth enrolled in higher education, more than half (59\%) were in community college, $14 \%$ were attending a vocational school and $27 \%$ were in a four year program. All control group youth enrolled in postsecondary education were in community college except one youth who was attending a fouryear university.

Given that the control and intervention groups differed slightly at $\mathrm{T} 1$ with regard to being Juniors or Seniors in high school, and thus being in the expected window for transition to higher education, the analyses examined the high school graduation rates and postsecondary enrollment for just youth who were seniors or working on their GED at the time of study enrollment. The data for these youth at the end of the follow along period reveals similar high school graduation rates for the two groups (88.2\% for intervention vs. $84.6 \%$ for control). However, the two groups differed significantly in their participation in postsecondary education at T4 (72.7\% for intervention vs. $35.7 \%$ for control). Pearson Chi-Square analyses revealed this group difference was statistically significant at $p=.028$.

Employment. At the time of enrollment, five (16\%) control group youth and one intervention youth (3\%) were working at least part-time. At the end of the study period (T4), nine (36\%) control group and eleven (32\%) intervention group youth had paid employment. When asked about unpaid work experience at baseline (e.g. job shadow, internships), nine (29\%) control and sixteen (46\%) intervention youth were engaged in part-time volunteer work; participation decreased at $\mathrm{T} 4$ to seven (28\%) control and ten (29\%) intervention youth. This decrease, in part, may reflect paid employment in both group experienced at T4, as well as the increasing participation in higher education.

Living Situation. While all youth were in foster care at the time of enrollment, a substantial number of youth had exited care by the end of the project. At T4, eight (28\%) control youth had exited foster care; amongst youth who had exited care on their own, three were living with friends, three were living with relatives and one was married and living with her husband; an additional youth exited foster care because she had been adopted. Among control youth still in foster care, eleven (44\%) were in nonrelative foster care, five (20\%) were in kinship care, and one was residing in a group home. At the end of the study period, twelve intervention group youth had exited foster care (34\%); nine had exited care on their own and three had been formally reunited with their biological family. Among the nine intervention youth who left foster care on their own, 
eight were living with friends and one youth was living alone in an apartment. Among the intervention youth still in foster care at the end of the study, nine were in a non-relative foster care placement, seven were in kinship care, two lived in a group home, and five youth were residing in a dorm room at college.

\section{Mixed Models Analysis of Other Key Outcomes}

The distribution of each variable at each time point was examined; approximately half had reasonable distributions (symmetric and unimodal) and a linear mixed model was used for analysis. Several variables, however, had appreciable skew that required accommodation. All but one of these (the AIR self-determination scale) were positively skewed; the AIR was reverse scored to make it positively skewed as well, and a non-linear mixed model was used, specifying a Poisson distribution with a $\log$ link function. Mixed models are the method of choice for longitudinal data as they make use of all the available data, with no list-wise deletions. In addition, they provide more options for modeling the variance-covariance matrix, compared to traditional repeated measures models.

We also examined each outcome for the appropriate form of the variance covariance matrix among observations. Either an unstructured, heterogeneous compound symmetric, or homogeneous compound symmetric matrix was estimated depending on which structure best fit the data using the log likelihood or pseudo-log likelihood, in the case of the non-linear model.

In addition to the omnibus test of each effect (condition, time, condition by time, gender, age, of which the latter two were included as controls), estimates which disassociated the interaction term using contrasts of the differences in time points between groups were included. Because there were six possible contrasts (Time 1 vs. Time 2, Time 1 vs. Time 3, Time 1 vs. Time 4, Time 2 vs. Time 3, Time 2 vs. Time 4, and Time 3 vs. Time 4) by group, a more stringent type I error rate (.01) for these comparisons was used. The Kenward-Roger technique was specified to estimate the degrees of freedom in the mixed models. Effect sizes were formed by taking the values of the contrasts and dividing by an estimate of the standard deviation. With the linear mixed model, usage of the estimate of the variance at baseline when the structure of the variance-covariance matrix was unstructured or heterogeneous compound symmetric, or the overall variances when the variance-covariance structure was compound symmetric. With nonlinear mixed models, the means were back transformed into the original units, and the differences divided by the pooled estimate of the time one standard deviation. Means and standard deviations are presented in Table 2.

\section{Self Determination}

Arc Self-determination Scale. The ARC, which has a total sum score ranging from $0-148$, was relatively symmetric and unimodal in form and so a linear mixed model was utilized. The structure of the variance-covariance matrix was consistent with compound symmetry and so this form was specified. Results of the model indicated a significant condition effect, $F(1,61.1)=13.31 ; p=0.0005$, a significant time effect, $F(3,178)=9.88 ; p<0.0001$, and, more importantly, a significant group by time interaction, $F(3,178)=3.74 ; p=0.0122$. Results of the individual contrasts suggested a significant difference between Times 1 and 4 in favor of the experimental group, $t(179)=3.32 ; p=0.0011$, effect size $=0.74$. The differences between Time 2 and Time 4, $t(179=2.08 ; p=0.0392$; effect size $=0.47$, and Time 3 and Time 4, $t(178)=2.06 ; p=0.0409$; effect size $=0.47$, were significant at the .05 level but did not reach the more stringent .01 level. Figure 1 shows the means by group and time.

AIR Self-Determination. Total sum scores can range from 24-120; this scale was skewed in a negative direction, requiring scores to be reverse coded before applying a nonlinear mixed model. The variance-covariance matrix was complex in form, requiring an unstructured matrix be estimated. The results indicated a significant group effect, $F(1,62)$ $=13.63 ; p=.0005$, but no time effect or group by time interaction. When examining the contrasts, none of those by time were significant. Simple main effects, comparing the groups at each time, indicated that the treatment group had higher scores (in 
Table 2. Means and standard deviations by study group

\begin{tabular}{|c|c|c|c|c|}
\hline \multirow[b]{2}{*}{ Measurement Time/Instrument } & \multicolumn{2}{|c|}{ Control Group } & \multicolumn{2}{|c|}{ Intervention } \\
\hline & $M$ & SD & $M$ & SD \\
\hline \multicolumn{5}{|l|}{ Time 1} \\
\hline AIR Self-Determination Scale & 87.58 & 16.56 & 95.00 & 16.80 \\
\hline Arc's Self Determination Scale & 96.47 & 20.54 & 105.15 & 16.41 \\
\hline Quality of Life Questionnaire & 81.14 & 10.38 & 83.05 & 8.96 \\
\hline Hopelessness Scale for Children & 28.97 & 6.74 & 28.02 & 5.31 \\
\hline Youth Efficacy/Empowerment Scale & 3.58 & .59 & 3.44 & .54 \\
\hline Mental Health Recovery Measure & 89.68 & 15.87 & 87.85 & 14.46 \\
\hline Transition Planning Assessment & 2.01 & .68 & 2.12 & .66 \\
\hline Career Decision Self Efficacy Scale & 3.41 & .92 & 3.56 & .72 \\
\hline Assessing Barriers to Education & 79.77 & 24.26 & 68.14 & 14.50 \\
\hline Postsecondary Preparation Scale & 6.74 & 5.06 & 6.48 & 4.53 \\
\hline \multicolumn{5}{|l|}{ Time 2} \\
\hline AIR Self-Determination Scale & 88.64 & 19.76 & 98.00 & 13.82 \\
\hline Arc's Self Determination Scale & 93.34 & 21.07 & 106.87 & 16.40 \\
\hline Quality of Life Questionnaire & 80.74 & 11.58 & 87.68 & 12.35 \\
\hline Hopelessness Scale for Children & 31.41 & 8.01 & 26.50 & 6.90 \\
\hline Youth Efficacy/Empowerment Scale & 3.53 & .66 & 3.76 & .58 \\
\hline Mental Health Recovery Measure & 87.06 & 19.04 & 93.20 & 16.32 \\
\hline Transition Planning Assessment & 2.21 & .73 & 2.65 & .66 \\
\hline Career Decision Self Efficacy Scale & 3.47 & .93 & 4.08 & .80 \\
\hline Assessing Barriers to Education & 72.61 & 21.91 & 65.52 & 16.79 \\
\hline Postsecondary Preparation Scale & 7.58 & 5.57 & 11.51 & 4.10 \\
\hline \multicolumn{5}{|l|}{ Time 3} \\
\hline AIR Self-Determination Scale & 87.87 & 19.31 & 99.42 & 11.87 \\
\hline Arc's Self Determination Scale & 98.75 & 21.90 & 113.09 & 18.73 \\
\hline Quality of Life Questionnaire & 84.68 & 13.57 & 87.10 & 14.90 \\
\hline Hopelessness Scale for Children & 32.24 & 7.25 & 26.46 & 7.83 \\
\hline Youth Efficacy/Empowerment Scale & 3.50 & .65 & 3.62 & .95 \\
\hline Mental Health Recovery Measure & 86.52 & 19.18 & 94.03 & 16.34 \\
\hline Transition Planning Assessment & 2.35 & .69 & 2.85 & .73 \\
\hline Career Decision Self Efficacy Scale & 3.51 & .79 & 4.21 & .69 \\
\hline Assessing Barriers to Education & 73.23 & 22.54 & 62.13 & 17.83 \\
\hline Postsecondary Preparation Scale & 10.42 & 6.50 & 17.18 & 4.95 \\
\hline
\end{tabular}

(Continued on next page) 
Table 2. Means and standard deviations by study group (continued)

\begin{tabular}{lcccc}
\hline & \multicolumn{2}{c}{ Control Group } & \multicolumn{2}{c}{ Intervention } \\
\cline { 2 - 5 } Measurement Time/Instrument & $\boldsymbol{M}$ & SD & M SD \\
\hline Time 4 & & & & \\
\hline AIR Self-Determination Scale & 89.99 & 17.92 & 103.97 & 11.04 \\
Arc's Self Determination Scale & 99.97 & 17.45 & 121.80 & 16.35 \\
Quality of Life Questionnaire & 85.40 & 10.72 & 93.86 & 10.86 \\
Hopelessness Scale for Children & 32.70 & 7.21 & 26.50 & 6.07 \\
Youth Efficacy/Empowerment Scale & 3.34 & .54 & 4.07 & .56 \\
Mental Health Recovery Measure & 87.65 & 14.73 & 96.56 & 19.86 \\
Transition Planning Assessment & 2.20 & .69 & 3.01 & .68 \\
Career Decision Self Efficacy Scale & 3.48 & .76 & 4.44 & .51 \\
Assessing Barriers to Education & 83.66 & 22.96 & 55.09 & 12.10 \\
Postsecondary Preparation Scale & 10.70 & 6.07 & & 19.05 \\
\hline
\end{tabular}

the original units) than the control group although this difference was significant only at Time $3, t(62)$ $=-3.08 ; p=0.0031$; effect size $=-0.71$, and $4, t(62)$ $=-3.81 ; p=.0003$; effect size $=-0.88$. The difference between groups at Time 2 was close to significant at the .01 level, $t(62)=-2.285 ; p=.0261$; effect size $=$ -0.53 , but smaller at Time 1, $t(62)-1.78 ; p=.0795$; effect size $=-0.47$. So, while the difference got greater over time, they were not large enough, relative to the variability, for the group by time interaction to be significant (see Figure 2).

\section{Mental Health}

Youth Efficacy / Empowerment Scale-Mental Health. Mean sum scores on this measure range from 1-5. The distributional form was symmetric and unimodal; however, while the covariances were approximately equal, the variances were not and thus a mixed model with heterogeneous compound symmetric matrix was fit to the data. The results showed a significant group by time interaction, $F(3$, $118)=9.07 ; p<.0001$. Time 4 was higher than Time $1, t(111)=5.17 ; p<0.0001$; effect size $=1.50$, Time 2 , $t(107)=2.94 ; p=.0004$; effect size $=0.87$, and Time $3, t(89.4)=2.76 ; p=.0071$; effect size $=1.05$, for the treatment group compared to the control group; the change from Time 1 to Time 2 was greater for the treatment group as well, $t(112)=2.16 ; p=0.037$, effect size $=0.63$, but did not meet the .01 significance criterion (see Figure 3).

Mental Health Recovery Measure. The measure, which could range in total sum scores from 30-150, was relatively symmetric and unimodal, and since the variances were approximately equal as were the covariances, a compound symmetric variance-covariance matrix was specified for the analysis. While there was no significant group or time effects here, the group by time interaction approached significance in favor of the intervention group, $F(3,180)=2.55 ; p=0.0569$. None of the contrasts reached significance at the .01 level but the group differences between Time 1 and Time $3, t(180)=2.14 ; p=0.0341$; effect size $=0.53$, and $4, t(181)=2.5 ; p=0.0132$; effect size $=0.63$, also approached significance (see Figure 4).

Youth Self-Report Form. There were no significant time or group differences.

\section{Quality of Life}

Quality of Life Scale. The measure, which ranges in total sum scores from 40-120, was 
Figure 1. Arc Self-Determination
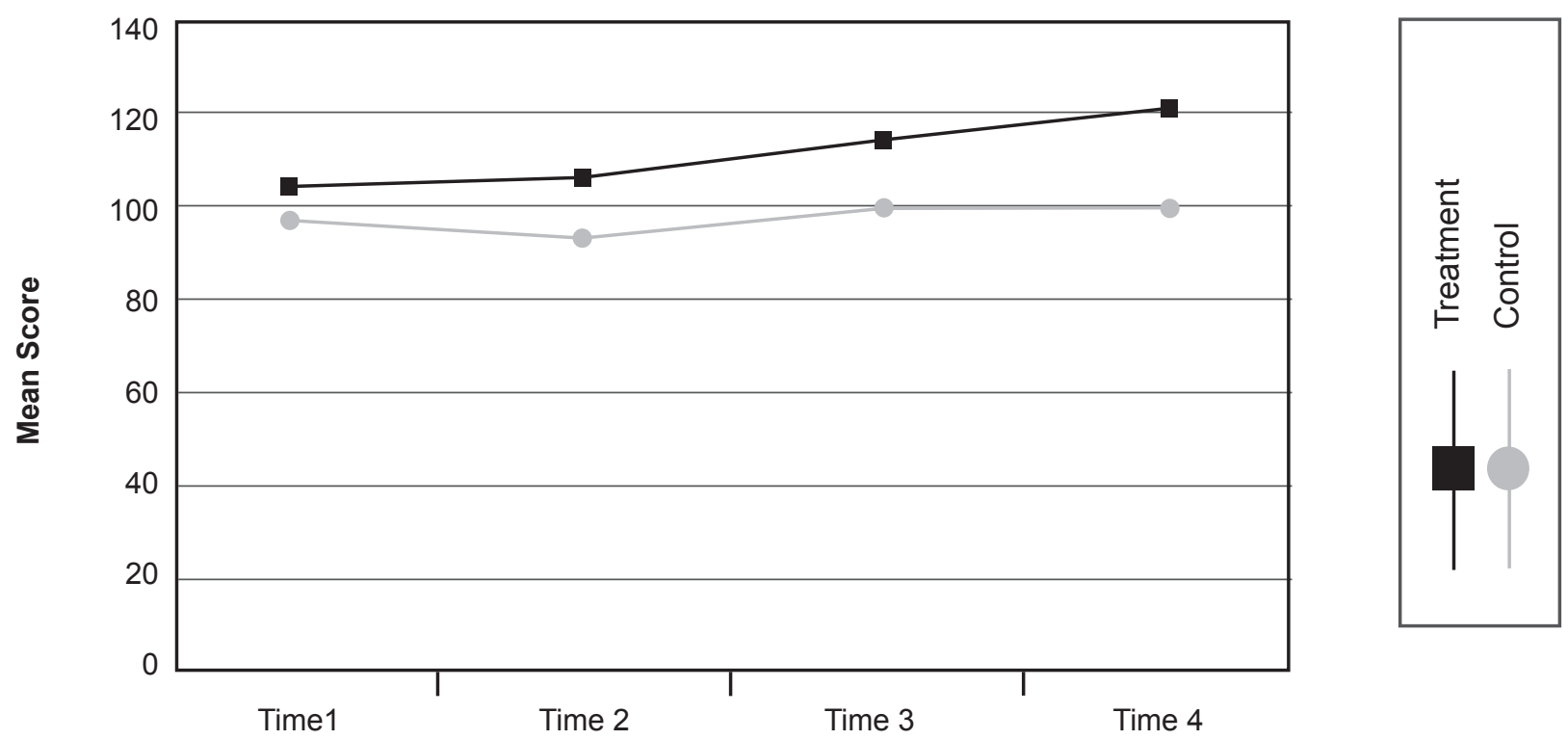

Figure 2. AIR Self-Determination

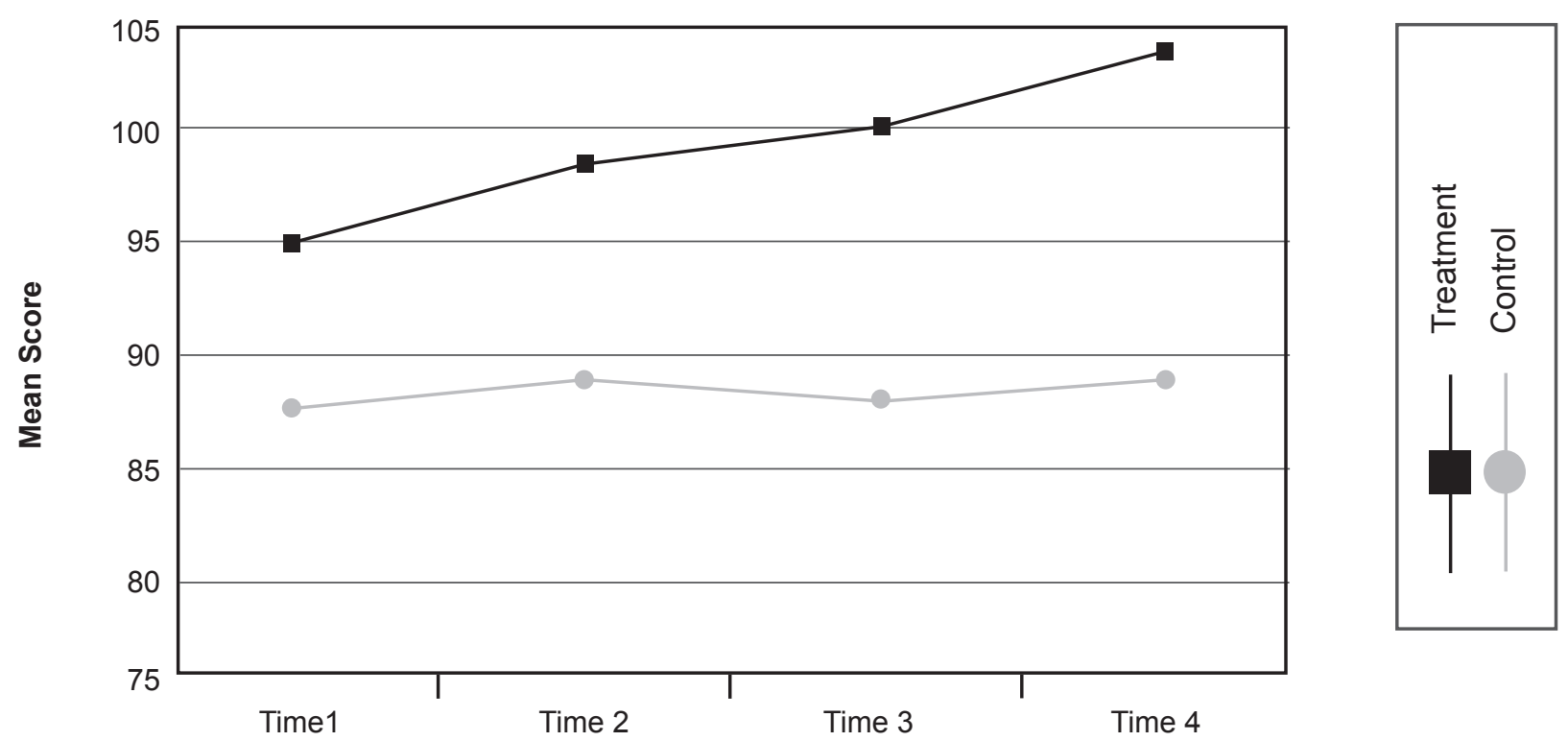


Figure 3. Youth Efficacy/Empowerment Scale

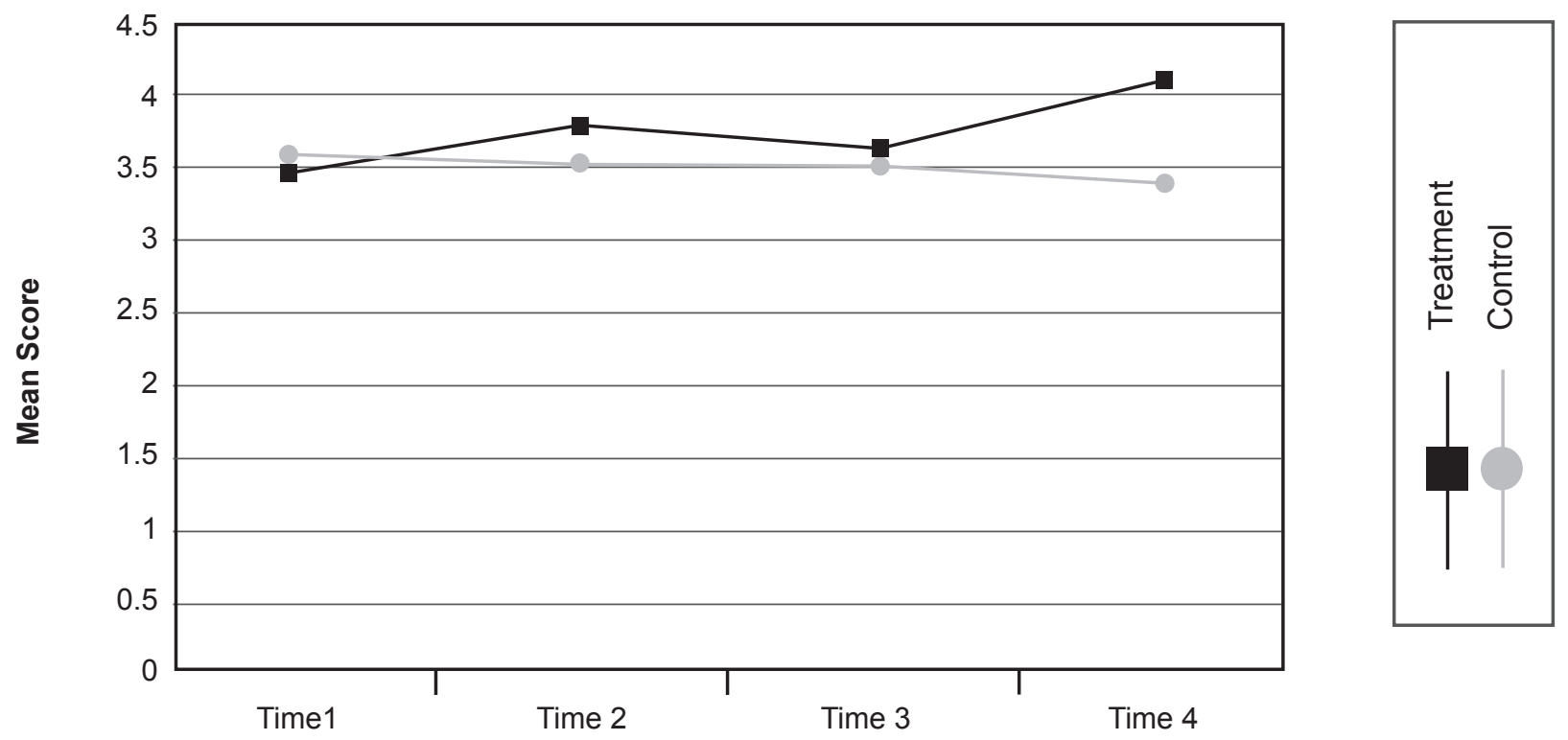

relatively symmetric and unimodal and, while the covariances were approximately equal, the variances were not; thus a linear mixed model with heterogeneous compound symmetric structure was used. There was no group by time interaction, $F(3$, $118)=2.29 ; p=0.0816$, but there was a significant group, $F(1,62.1)=4.27 ; p=0.0429$, and time effect, $F(3,118)=9.40 ; p<0.0001$. However, none of the contrasts met the more stringent type I error rate, although the group difference between Times 1 and 4 approached significance, $t(106)=2.22 ; p=$ .0287 ; effect size $=0.66$. As highlighted in the graph (Figure 4) there was a slight dip from time 2 to time 3 for the treatment group and a strong increase for the control group between these times. However the treatment group rebounded between times 3 and 4 whereas the control group was stable (Figure 5).

\section{Hope}

The Hopelessness Scale. This scale, with possible sum scores of 17-68, was positively skewed and thus a nonlinear mixed model was used for the analysis. The variance-covariance matrix was complex and required an unstructured format. The analysis revealed a significant group effect, $F(1,62)$
$=10.67 ; p=0.0018$, but, more importantly, a significant group by time interaction, $F(3,62)=2.79$; $p=.0479$. Contrasts showed that Time 4 was significantly lower than Time 1 of the treatment group than controls, $t(62)=-2.83 ; p=.0063$; effect size $=$ -0.91 , and the difference between Times 1 and 2, $t(62)=2.14 ; p=.0360$; effect size $=-0.67$, and Times 1 and $3, t(62)=-2.34 ; p=0.0227$; effect size $=-0.74$, neared but did not reach the more stringent level of significance (Figure 6).

\section{Postsecondary and Transition Planning}

Career Decision Self-Efficacy Scale. This measure had a range of mean sum scores from 1-5, and was symmetric and unimodal. Although the covariances were similar, the variances differed over time (typically declining), indicating a heterogeneous compound symmetric form for the variance-covariance matrix. There was a significant effect of group, $F(1,61.2)=16.30 ; p=0.0002$, time, $F(3,124)=7.51$; $p=0.0001$, and group by time, $F(3,124)=6.06 ; p=$ .0007 . The contrasts indicated that the differences between the groups for Time 1 vs. Time $4, t(112)$ $=4.27 ; p<0.0001$; effect size $=1.00$, and Time 1 to Time 3, $t(115)=2.71 ; p=0.0077$; effect size $=0.65$, 
Figure 4. Mental Health Recovery Measure

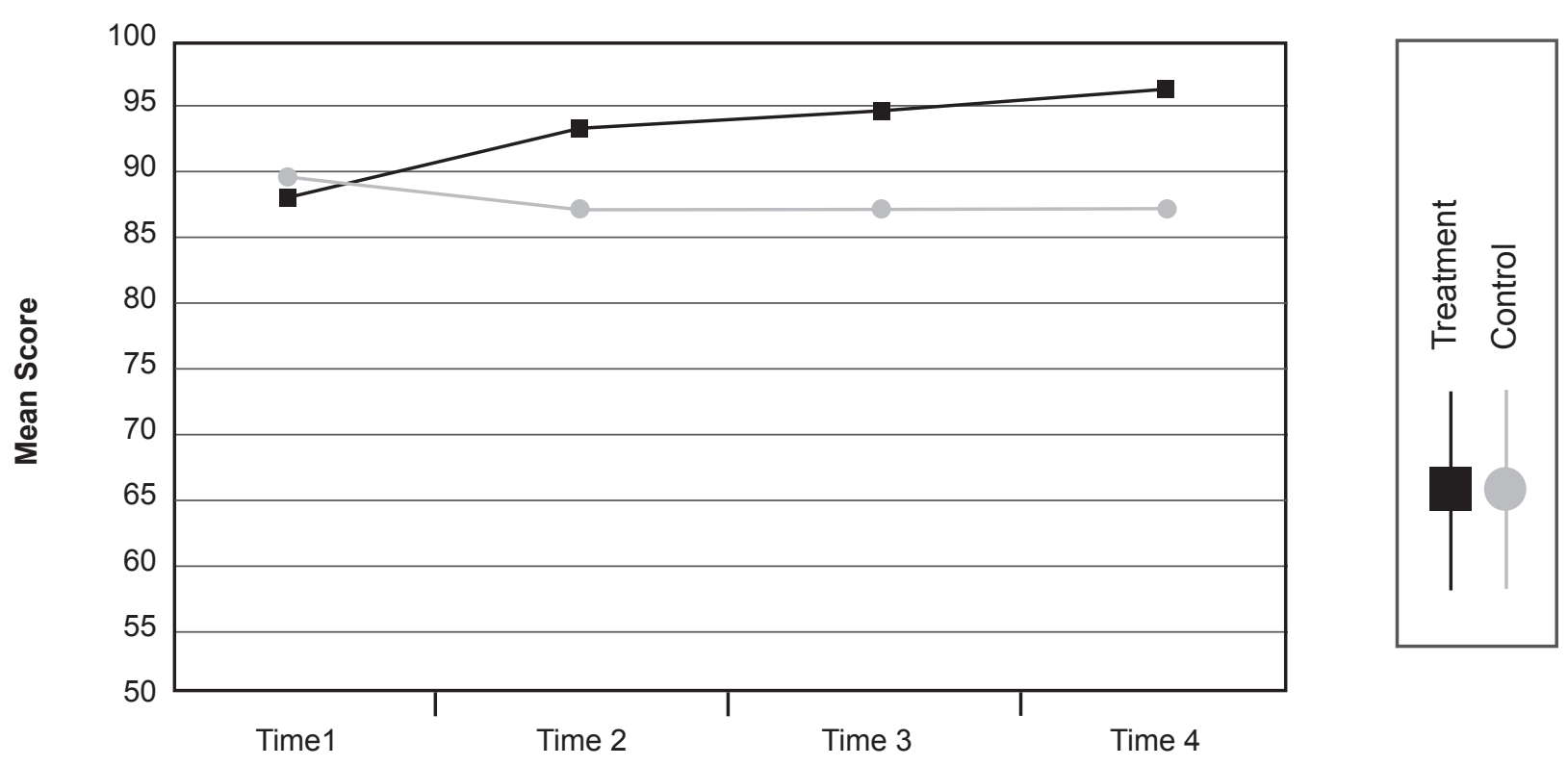

Figure 5. Quality of Life Scale

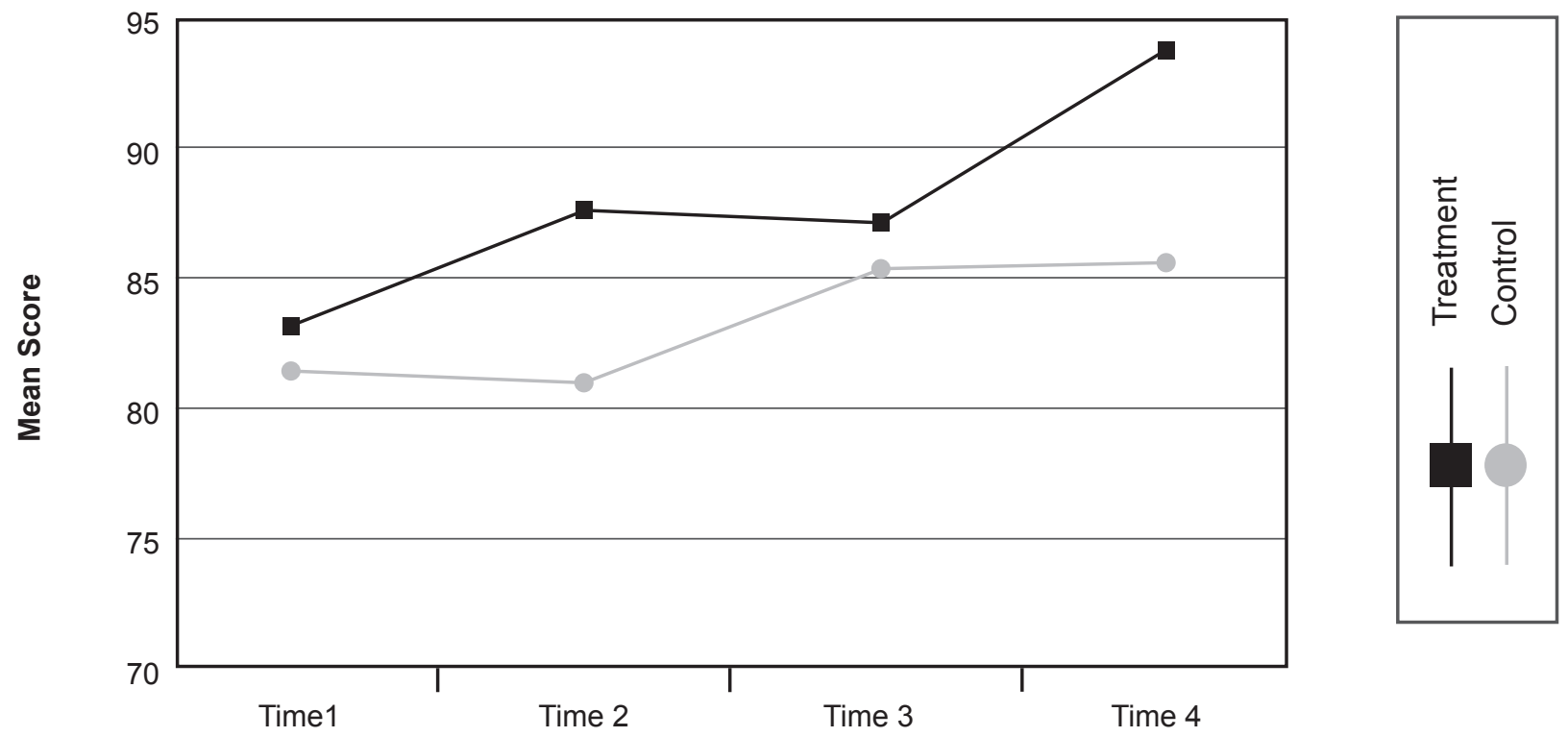


were significant and the difference between Time 1 and Time 2, $t(118)=2.18 ; p=0.0313$; effect size $=0.55$, was close but did not quite reach the more stringent type I error rate (Figure 7).

Assessing Barriers to Education. This scale, with sum scores ranging from 40-160, had a positively skewed distribution and thus was subjected to a nonlinear mixed models analysis. The variancecovariance structure was complex and an unstructured form of the matrix estimated. The group effect, $F(1,62)=15.45 ; p=0.0002$, and the group by time interaction, $F(3,62)=6.49 ; p=0.0007$, were statistically significant. Contrasts indicated that Time 4 was significantly lower than Time $1, t(62)=$ -2.86; $p=.0058$; effect size $=-0.84,2, t(62)=3.88$; $p=.0002$; effect size $=1.07$, and $3, t(62)=3.88 ; p=$ .0003 ; effect size $=0.91$, in the treatment group than in controls, indicating that youth in the intervention group experienced a greater reduction in perceived barriers over time (see Figure 8).

Post-secondary Preparation Questionnaire. This scale, which had a sum score range of 0-24, was relatively symmetric and unimodal, with a compound symmetric variance-covariance structure. The linear mixed model demonstrated significant effects for group, $F(1,62.2)=21.72 ; p<$ 0.0001 , time, $F(3,12)=62.55 ; p<0.0001$, and group by time, $F(3,182)=17.27 ; p<0.0001$. Differences between groups were significant for Time 1 vs. Time 2, $t(180)=3.29 ; p=0.0012$; effect size $=0.82$, Time 1 and Time 3, $t(182)=5.33 ; p=0.0001$; effect size $=1.36$, and Times 1 and $4, t(183)=6.73 ; p<$ 0.0001 ; effect size $=1.75$, and times 2 and $4, t(183)$ $=3.58 ; p=0.0004$; effect size $=0.93$. The difference between groups for Time 2 vs. Time 3 approached significance, $t(182)=2.14 ; p=0.0340$; effect size $=$ 0.55 (Figure 9).

Transition Planning Assessment. The measure, which ranges in mean sum score from 1-4, was symmetric and unimodal with a variance-covariance structure that was compound symmetric. The mixed model indicated a group effect, $F(1,61.7)=$ $14.73 ; p=0.0003$, time effect, $F(3,182)=11.50 ; p$ $<.0001$, and group by time interaction, $F(3,182)=$ $3.50 ; p=.0168$. The contrasts reflected a significant difference between groups from Time 1 to Time 4, $t(183)=3.23 ; p=0.0015$, effect size $=1.00$. While there were moderate effect sizes for the differences

Figure 6. Hopelessness Scale
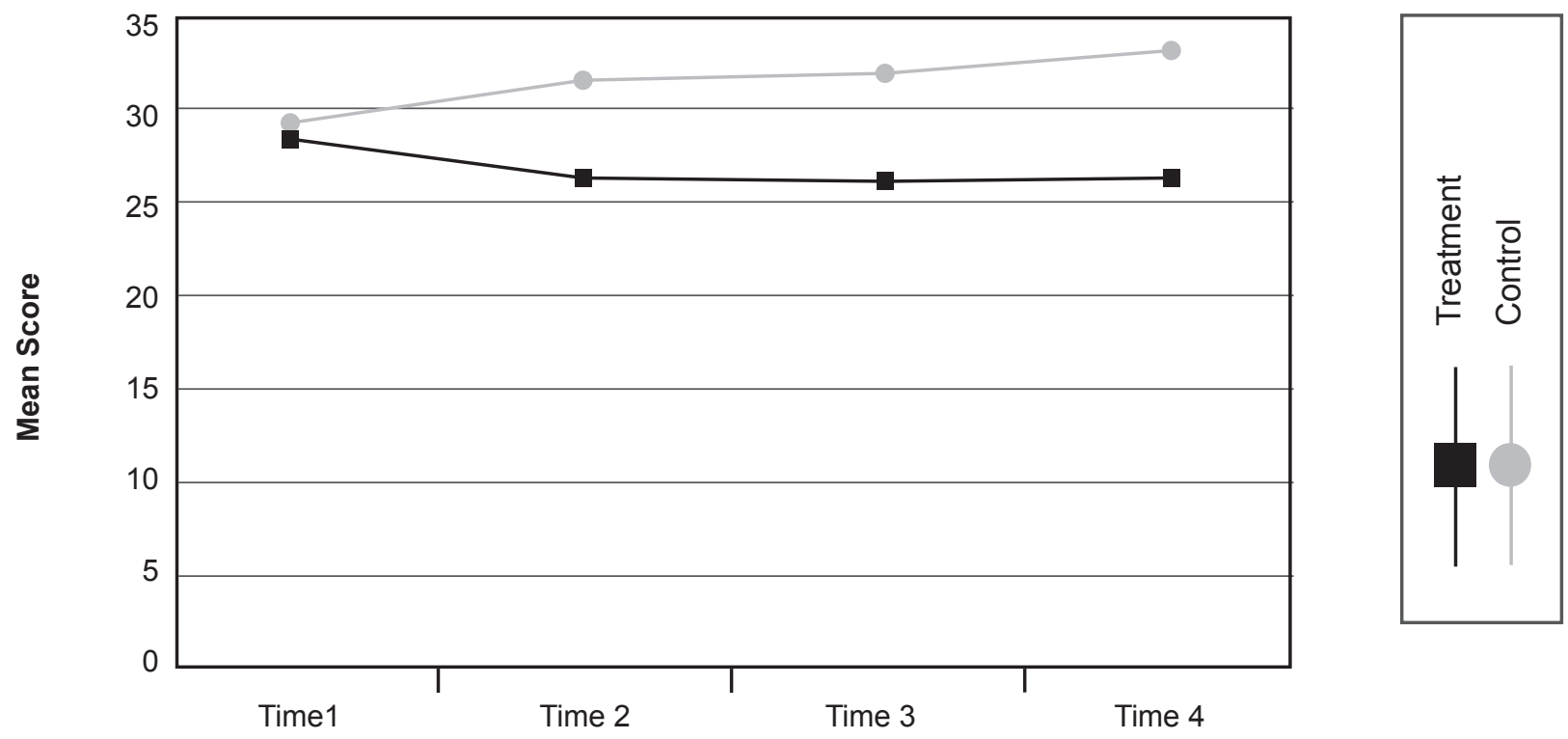

Better Futures: a Randomized Field Test of a Model for Supporting Young People... 
Figure 7. Career Decision Self-Efficacy Scale
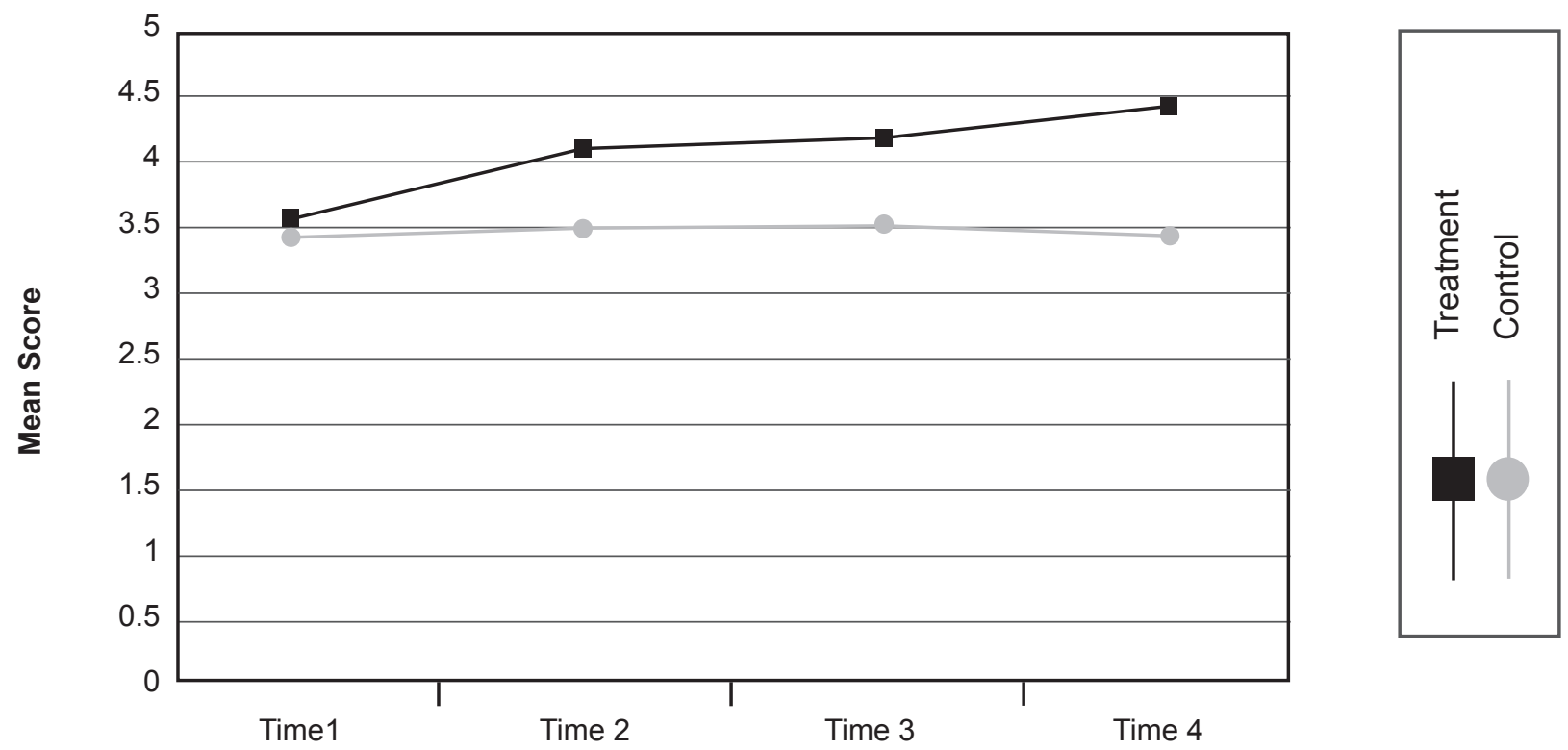

Figure 8. Assessing Barriers to Education
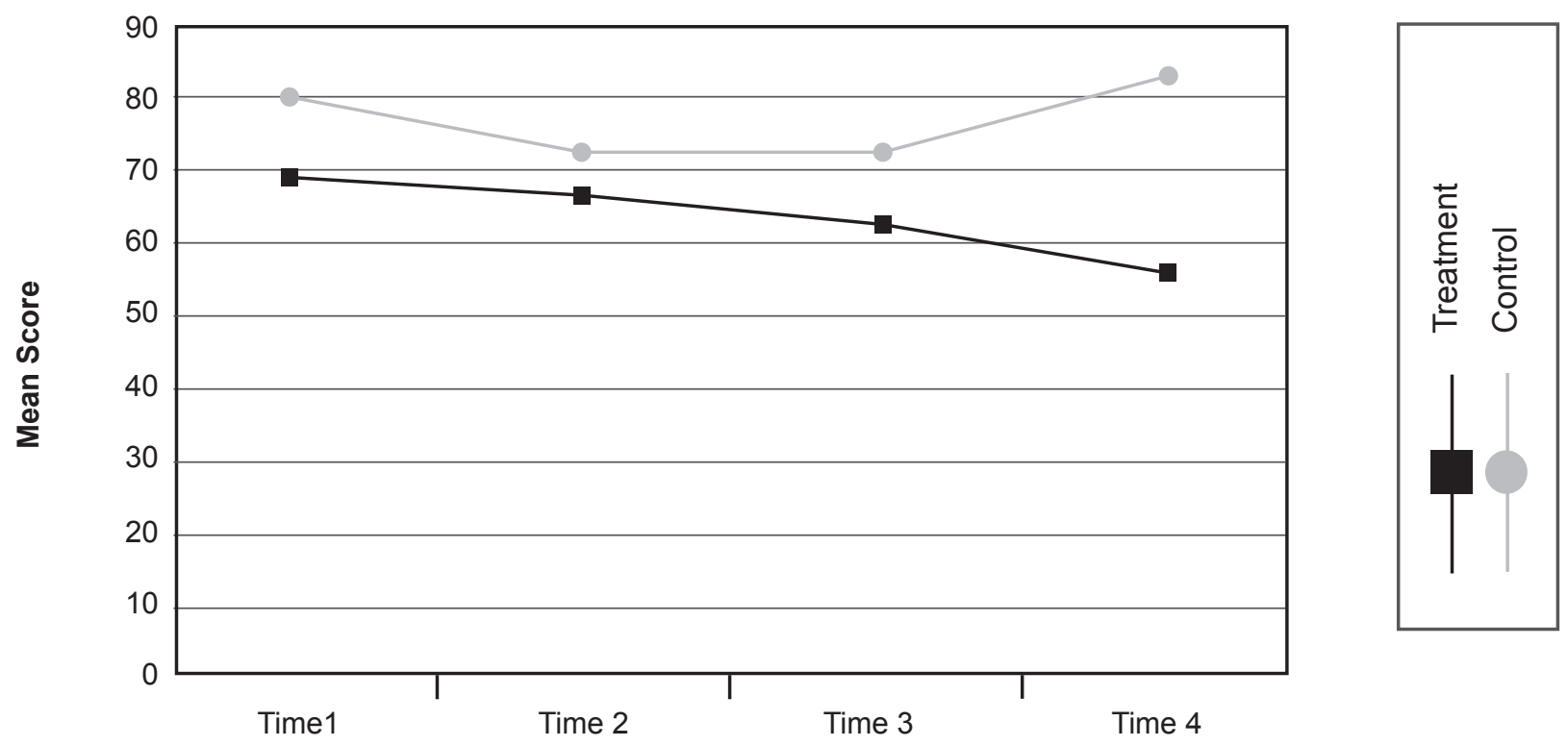


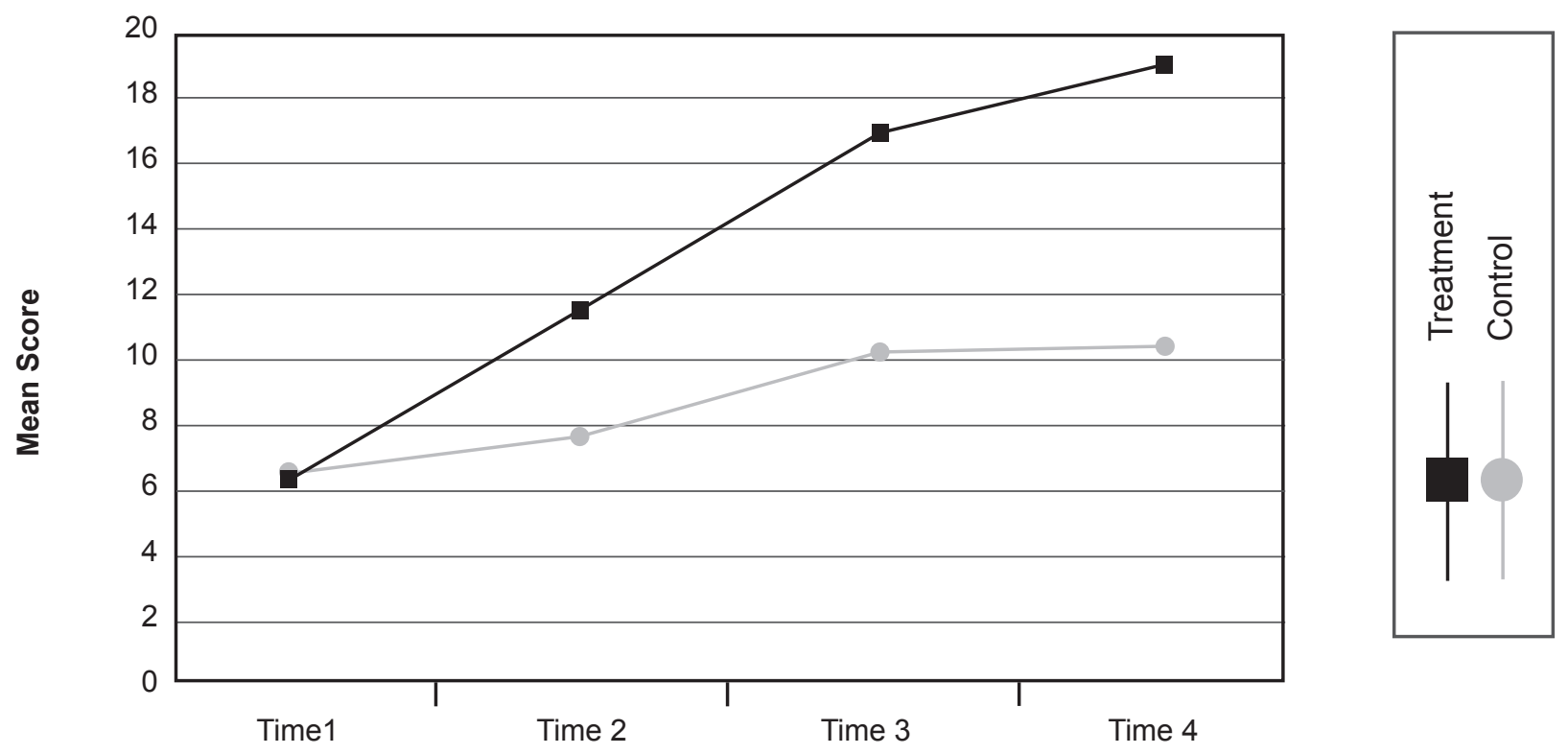

between groups for Time 1 to Time 2 (effect size $=$ 0.47 ), Time 1 to Time 3 (effect size $=0.53$ ), Time 2 to Time 4 (effect size $=0.53$, and Time 3 to Time 4 (effect size $=0.48$ ), they did not reach significance at the 0.01 level (Figure 10).

\section{Discussion}

These findings provide the first experimental, longitudinal evidence of the efficacy of the Better Futures model, and the study is the first to experimentally evaluate any intervention to increase the postsecondary participation of youth in foster care and/or with mental health issues. Foremost, youth in Better Futures achieved twice the level of postsecondary participation at follow-up, compared to the control group. Significant omnibus group differences also were detected from baseline to intervention follow-up on measures of self-determination, mental health empowerment, postsecondary preparation, transition planning, and hope; moderate to large effect sizes were observed for the differences between groups. Youth in the intervention group also showed promising trends towards higher rates of high school completion, mental health recovery and quality of life, as compared to youth in the comparison group. The relatively small sample size most likely left the study underpowered to detect additional significant omnibus and time contrast effects across these measures. Nevertheless, these findings compellingly demonstrate that youth in foster care with mental health issues can successfully break down the doors of higher education and realize increasing confidence, self-direction, hope, and wellness, when they have strengths-based and youth-directed support and opportunities that respond to their goals. Future study replication with a larger sample is warranted, as well as evaluation of the model's effects on postsecondary retention. Additional research also is needed to better understand the influence of contextual factors, such as the higher education experiences of caregivers (e.g. foster parents), and to carefully evaluate the detailed costs (and relative savings) associated with implementing the intervention, which would be useful in planning for larger scale implementation and adoption of the model. 

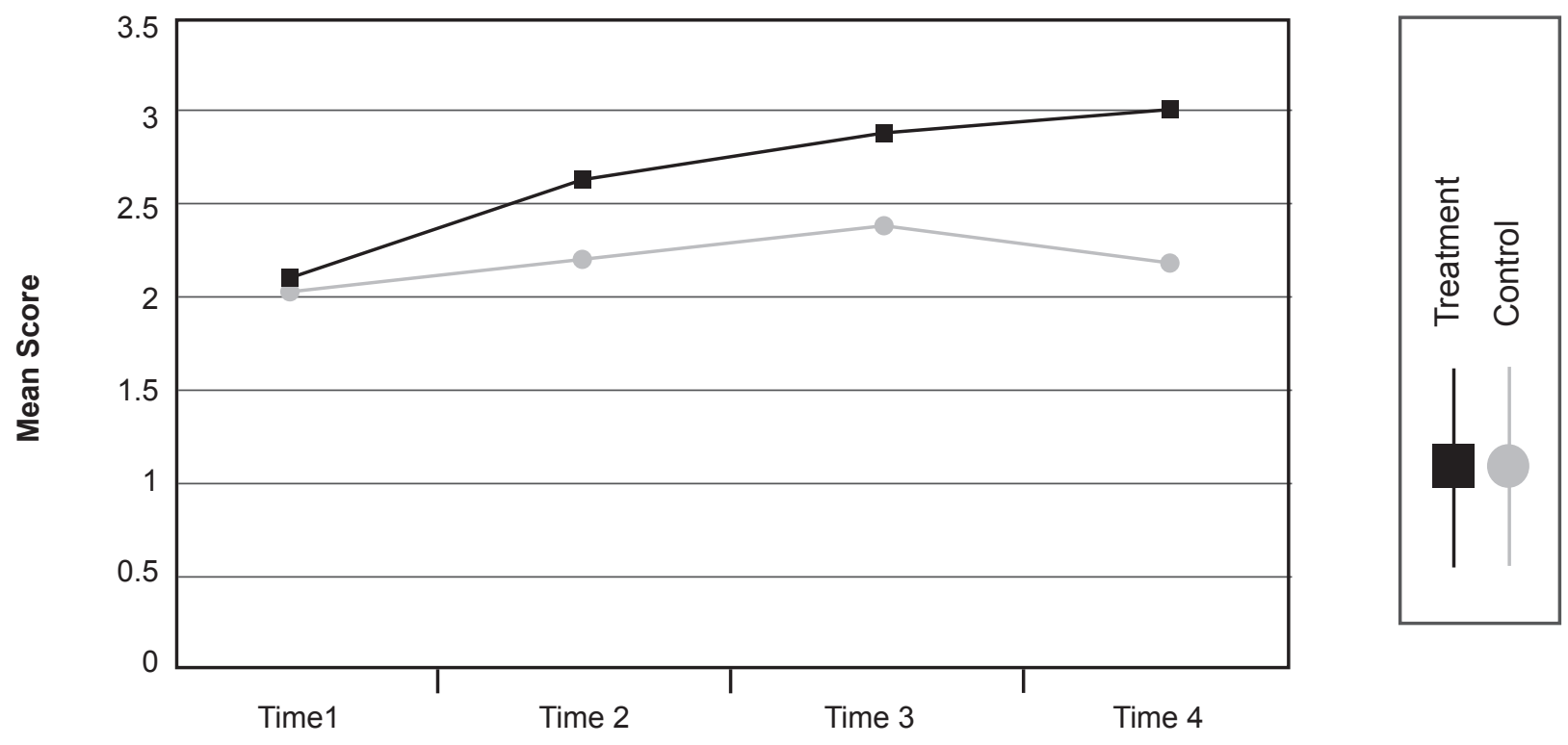

As highlighted across most of the findings, the Summer Institute and subsequent coaching and mentoring experience seem to have additive effects. Future research could investigate whether the Institute sets a youth's initial course, while peer coaching and mentoring support the trajectory set, and/ or whether the Institute provides youth with an initial boost of knowledge, encouragement, and confidence that prepares them to utilize coaching and mentoring to achieve their higher education goals over the subsequent nine months. More detailed mixed-method examination of the temporal associations among intervention elements and variables identified as important in this study would advance understanding of these questions.

While other approaches exist to promote the postsecondary engagement of youth in foster care, the Better Futures intervention model is unique in several respects. Mental health and wellness are integrated throughout the model; approximately $70 \%$ of youth participating in the intervention were engaged in mental health services, with almost half taking mental health medication. Youth are system- atically supported over time with a fidelity-driven, carefully evaluated approach. Active outreach engages many youth who have struggled in school and doubt that postsecondary education is a reachable goal. Almost one-third of youth participating in the intervention received special education services and $8 \%$ received Developmental Disability Services. And of particular importance, the model's centerpiece is near-peer, self-determination-based support. In this regard, qualitative and social validity findings reported elsewhere ${ }^{39,55}$ highlight the important benefits of near peer support and further research is needed to explore the processes and strengths of the near peer model in greater depth; for example, a closer investigation of how other shared characteristics between the youth and nearpeer (e.g. gender, ethnicity, similar interests) contribute to the relationship may be helpful in determining which matches will be most successful.

\section{Limitations}

Several important limitations exist in interpreting the findings from this randomized trial. As 
previously mentioned, the relatively small sample size likely resulted in the study being statistically underpowered, as well as limiting generalizability While a more stringent Type I error rate was used in comparisons, the small sample size nevertheless leaves open the potential for multiplicity in measuring multiple outcomes. The study's placement in a single mid-sized urban setting on the west coast also limits generalizability of the findings to youth in other locales. Further, most of the measures had established psychometric properties, however a few were less well-documented (e.g., Postsecondary Preparation, Adapted Mental Health Recovery Measure). Finally, collection of qualitative data would have strengthened the study. While youth finishing coaching completed a brief survey providing feedback on their involvement in the intervention, more in-depth interviews with participants or case study analysis would have been useful in assessing the contextual variables that either facilitate or inhibit the effectiveness of the intervention, as well as gathering more detailed information on how the intervention affects change in the selfdetermination and outcomes of participants.

\section{Implications for Behavioral Health}

While youth in foster care are significantly more likely than youth in the general population to experience a significant mental health condition, this is rarely addressed in programs designed to support their participation in higher education. However, as researchers such as Pecora ${ }^{56}$ and Sala$\mathrm{zar}^{57}$ have discovered when examining factors that lead youth in foster care to experience high levels of educational achievement, identifying and addressing mental health challenges are key components. For many of the youth, participation in Better Futures marked the first time they were exposed to discussions focused on acknowledging and normalizing their experience of mental health issues in the context of trauma, placement instability, social isolation, and other stressors associated with foster care and young adulthood. The intervention's emphasis on affirming their strengths, including the knowledge, skills, and resilience they developed through their foster care and mental health experi- ences, also was a unique reframing experience for many of the youth. Likewise, while the intervention focused foremost on supporting postsecondary preparation, many youth experienced other stressful life events, such as placement changes, parenthood, and/or mental health crises. During these events, coaches continued to offer caring presence, highlighting youth's strengths and supporting them with broader decision-making as well as with continuing work on their higher education goals. Sometimes their contact preserved a degree of normality and hope for youth in the midst of chaos. It is the hope that findings from Better Futures will ultimately underscore the capacities of youth in foster care, youth with mental health issues, and youth having both experiences, to successfully prepare for and participate in higher education, when provided with youth-directed and responsive support. In this regard, it is important to highlight that many of the supports provided through Better Futures are available to other youth who have not been marginalized by these experiences and identities - for example, encouragement from a supportive adult, opportunities to visit colleges, help to complete financial aid forms and applications, and interaction with other youth who have similar educational goals and with adults who are already in college. Even the affirming support and resources offered by Better Futures related to mental health could be feasibly incorporated within other existing higher education promotion programs for youth in foster care, first generation and low income students, youth of color and other marginalized groups, and could be of universal benefit to many youth, regardless of whether they have formal mental health labels. It is the hope that knowledge gained from the Better Futures study will help to catalyze increased supports and access for youth with foster care and mental health experiences across the continuum of higher education services, making it possible for these youth, like many of their peers, to realize their dreams for high education.

\section{Conflict of Interest}

The authors do not have a conflict of interest. 


\section{Acknowledgments}

The Research Consortium to Increase the Success of Youth in Foster Care is dedicated to experimentally identifying approaches that improve the outcomes of young people in foster care. Other coauthors from the Research Consortium were Teresa Salinas, tsalinas@pcc.edu, Harry Zweben, harry. zweben@pcc.edu, and Wendy Palmer,wpalmer@ pcc.edu, Portland Community College; Diann Drummond, MS, dianndrummond@gmail.com, Portland Public Schools; Kevin George, kevin. george@state.or.us, and Rosemary Iavenditti, rosemary.iavenditti@state.or.us, Oregon Department of Human Services; Celeste Bodner, celeste@fosterclub.com, Foster Club; Elizabeth McHugh, LCSW, elizabeth.e.mchugh@multco.us, Developmental Disability Services; and Jackie Burr, MA, MS, Western Oregon University, Teaching Research Institute, jackburr777@gmail.com.

Better Futures is a project of the Pathways to Positive Futures Research and Training Center at the Regional Research Institute for Human Services at Portland State University. Please contact Sarah Geenen for further information (geenens@pdx. edu). The preparation of this article was funded, in part, by the National Institute of Disability and Rehabilitation Research, United States Department of Education, and the Center for Mental Health Services, Substance Abuse and Mental Health Services Administration, United States Department of Health and Human Services (NIDRR grant H133B090019). Agency endorsement of the information or opinions expressed herein should not be inferred.

\section{References}

1. U.S. Department of Health and Human Services, Administration for Children and Families, Children's Bureau. (2013). AFGARS preliminary report for FY 2012 (20) pp. 6. Available online at http://www.acf.hhs.gov/ programs/cb. Accessed January 5, 2014.

2. Courtney ME, Dworsky A. Early outcomes for young adults transitioning from out-of-home care in the USA. Child and Family Social Work. 2006; 11(3): 209-219.

3. Courtney ME, Dworksy A, Brown A, et al. Midwest evaluation of the adult functioning of former foster youth: outcomes at age 26. Chicago, IL: Chapin Hall Center for Children at the University of Chicago; 2011.

4. Goerge RM, Bilaver L, Lee BJ, et al. Employment outcomes for youth aging out of foster care. Chicago, IL: Chapin Hall Center for Children at the University of Chicago; 2002.

5. McMillen JC., Tucker, J. The status of older adolescents at exit from out-of-home care. Child Welfare. 1999; 78: 339-360.

6. Pecora PJ, Kessler RC, Williams J, et al. Improving family foster care: Findings from the Northwest Foster Care Alumni Study. Seattle, WA: Casey Family Programs; 2005.

7. Anctil TM, McCubbin LD, O’Brien K, et al. Predictors of adult quality of life for foster care alumni with physical and/or psychiatric disabilities. Child Abuse \& Neglect. 2007; 31(10): 1087-1100.

8. Edelman PB, Holzer HJ. Connecting the disconnected: Improving education and employment outcomes among disadvantaged youth. Bonn, Germany: Eza; 2013. Policy paper No. 56

9. Baum S, Mau J. Education pays 2007: The benefits of higher education for individuals and society. New York: College Board; 2007.

10. Institute for Higher Education. The investment payoff: A 50-state analysis of the public and private benefits of higher education. Washington, DC: Institute for Higher Education; 2005.

11. Peters C, Dworsky A, Courtney M, et al. Extending foster care to age 21: Weighing the costs to government against the benefits to youth. Chicago, IL: Chapin Hall, University of Chicago; 2009.

12. Rönkäa A, Oravala S, Pulkkinen L. Turning points in adults' lives: The effects of gender and the amount of choice. Journal of Adult Development. 2003; 10(3): 203-215.

13. Scanlon D, Mellard DF. Academic and participation profiles of school-age dropouts with and without disabilities. Council for Exceptional Children. 2002; 68(2): 239-258.

14. Courtney ME, Dworsky A, Lee J, et al. Midwest evaluation of the adult functioning of former foster youth: Outcomes at ages 23 and 24. Chicago, IL: Chapin Hall Center for Children at the University of Chicago; 2010.

15. McMillen C, Auslander W, Elze D, et al. Educational experiences and aspirations of older youth in foster care. Washington, DC: Child Welfare League of America; 2003. 
16. Tzawa-Hayden A. Take me higher: Helping foster youth pursue higher education. Child Law Practice. 2004; 23(10): 163-166.

17. National Working Group on Foster Care and Education. Fostering success in education: Natinal factsheet on the educational outcomes of children in foster care. Available online at http://www.fostercareandeducation. org/Database.aspx?EntryID=1279\&Command=Core Download\&method=inline Accessed January 27, 2014.

18. Courtney ME, Dworsky A, Cusick GR, et al. Midwest evaluation of the adult functioning of former foster youth: Outcomes at age 21. Chicago: Chapin Hall Center for Children at the University of Chicago; 2007.

19. Wagner M, Newman L, Cameto R, et al. Perceptions and expectations of youth with disabilities. A special topic report of findings from the National Longitudinal Transition Study-2 (NLTS2). Menlo Park, CA: SRI International; 2007. Available online at www.nlts2.org/ reports/2007_08/nlts2_report_2007_08_complete.pdf. Accessed December 10, 2013.

20. Newman L, Wagner M, Cameto R, et al. The post-high school outcomes of youth with disabilities up to 4 years after high school. A report of findings from the National Longitudinal Transition Study-2 (NLTS2) (NCSER 2009-3017). Menlo Park, CA: SRI International. Available online at www.nlts2.org/reports/2009_04/ nlts2_report_2009_04_complete.pdf. Accessed January 10,2014

21. Day A, Riebschleger J, Dworksy A, et al. Maximizing educational opportunities for youth aging out of foster care by engaging youth voices in partnership for social change. Children and Youth Review. 2012; 34(5): 1007-1014.

22. Dworsky, A, Perez A. Helping former foster youth graduate from college through campus support programs. Children and Youth Services Review. 2010; 32(2): 255-263.

23. Pecora PJ, Kessler RC, O’Brien, K, et al. Educational and employment outcomes of adults formerly placed in foster care: Results from the Northwest Foster Care Alumni Study. Children and Youth Services Review. 2006; 28: 1459-1481.

24. Wolanin TR. Higher education opportunities for foster youth: A primer for policymakers. Washington, DC: The Institute for Higher Education Policy; 2005.

25. Geenen S, Powers LE. (2006). Are we ignoring youths with disabilities in foster care: An examination of their school performance. Social Work. 2006; 51(3): 233-241.

26. Smithgall C, Gladden RM, Yang DH, et al. Behavior problems and educational disruptions among children in out-of-home care in Chicago. Chicago, IL: Chapin Hill; 2005.

27. Smithgall C, Jarpe-Ratner E, Walker L. Looking back, moving forward: Using integrated assessments to examine the educational experiences of children entering foster care. Chicago, IL: Chapin Hall at the University of Chicago; 2010.

28. Kerker BD, Dore MM. Mental health needs and treatment of foster youth: Barriers and opportunities. American Journal of Orthopsychiatry. 2006; 76(1): 138-147.

29. Quest AD, Fullerton A., Geenen S, et al. Voices of youth in foster care and special education regarding their educational experiences and transition to adulthood. Children and Youth Services. 2012; 34(9): 1604-1615.

30. Unrau YA, Font SA, Rawls G. Readiness for college engagement among students who have aged out of foster care. Children and Youth Services Review. 2012; 34: 76-83.

31. Singer ER, Berzin SC, Hokanson K. Voices of former foster youth: Supportive relationships in the transition to adulthood. Children and Youth Services Review. 2013; 35(12): 2110-2117.

32. Schmidt J, Cunningham M, Dalton L, et al. Assessing restrictiveness: A closer look at the foster care placements and perceptions of youth with and without disabilities aging out of care. Journal of Public Child Welfare. 2013; 7(5): 586-609.

33. Westat. A National Evaluation of Title IV-E Foster Care Independent Living Programs for Youth: Phase 2. (Contract No. OHDS 105-87-1608). U.S. Department of Health and Human Services. Rockville, MD: Author; 1991.

34. Courtney ME, Hughes-Heuring D. The transition to adulthood for youth "aging out" of the foster care system. In Osgood DW, Foster EM, Flanagan C, Ruth GR, eds. On your own without a net: The transition to adulthood for vulnerable populations. Chicago: The University of Chicago Press; 2005.

35. Hochman G, Hochman A, Miller J. Foster care: Voices from the inside. Pew Commission on Children in Foster care. Available online at http://pewfostercare.org/ research/voices/voices-complete.pdf 2004. Accessed January 30, 2014.

36. U.S. Government Accountability Office. Foster Youth: HHS actions could improve coordination of services and monitoring of States' independent living program (pp. 23). Washington, DC: Author; 2004.

37. Fried T. Community colleges step up to support foster care students. Community College Journal. 2008: 38-39.

38. Massinga R, Pecora PJ. (2004). Providing better oppor- 
tunities for older children in the child welfare system. The Future of Children: Children, Families and Foster Care. 2004; 14(1): 151-173.

39. Phillips LA, Oca S, Geenen S, et al. (2013). Better futures: Helping young people in foster care with mental health challenges prepare for and participate in higher education. Portland, OR: Portland State University, Pathways to Positive Futures Research and Training Center. Focal Point: Youth, Young Adults, \& Mental Health, Education and Employment. 2013; 27: 5-8.

40. Powers LE, Geenen S, Powers J, et al. My Life: Effects of a longitudinal, randomized study of self-determination enhancement on the transition outcomes of youth in foster care and special education. Children and Youth Services Review. 2012; 34(11): 2179-2187.

41. Casey Family Programs. It's my life: Postsecondary education and training. Seattle, WA: Author, 2006.

42. Geenen S, Powers LE, Powers J, et al. (2013). Experimental study of a self-determination intervention for youth in foster care. Career Development and Transition for Exceptional Individuals. 2013; 36(2): 84-95.

43. Jivanjee P, Kruzich J, Gordon L. Community integration of transition-age individuals: Views of young adults with mental health disorders. Journal of Behavioral Health Services \& Research. 2007; 35(4): 402-418.

44. Pistrang N, Barker C, Humphreys K. Mutual help groups for mental health problems: A review of effectiveness studies. American Journal of Community Psychology. 2008; 42(1-2): 110-121.

45. Phillips L, Powers LE, Geenen S, et al. Lessons learned and strategies for the successful implementation of the Better Futures model. Portland, OR: Portland State University, Pathways to Positive Futures Research and Training Center; 2014.

46. Wehmeyer ML, Kelchner K. The Arc's self-determination scale. Silver springs, MD: The Arc of the United States; 1995.
47. Wolman J, Campeau P, Dubois P, et al. AIR self-determination scale and user guide. Pal Alto, CA: American Institute for Research; 1994.

48. Walker JS, Thorne EK, Powers LE, et al. Development of a scale to measure the empowerment of youth consumers of mental health services. Journal of Emotional and Behavioral Disorders. 2010; 18(1): 51-59.

49. Young SL, Bullock WA. The mental health recovery measure. Toledo, $\mathrm{OH}$ : University of Toledo, Department of Psychology (\#918); 2003.

50. Achenbach TM. Manual for the youth self-report and 1991 profile. Burlington, VT: University of Vermont, Department of Psychiatry; 1991.

51. Schalock RL, Keith KD. Quality of life questionnaire. IDS Publishing Corporation; 1993.

52. Kazdin AE, Rodgers A, Colbus D. The Hopelessness Sale for Children: Psychometric characteristics and concurrent validity. Journal of consulting and Clinical Psychology. 1986; 54(2): 241-245.

53. Benz NE, Klein KL, Taylor KM. Evaluation of short form of the Career Decision-Making Self-efficacy Scale. Journal of Career Assessment. 1996; 4(1): 47-57.

54. Liptak JL Assessing barriers to education. Indianapolis, IN: JIST Publishing; 2008.

55. Croskey A, Jivanjee P. A study of the near-peer mentor experience from young adult and coach perspectives. Portland, OR: Portland State University, Pathways to Positive Futures Research and Training Center; 2014.

56. Pecora PJ. Maximizing educational achievement of youth in foster care and alumni: Factors associated with success. Children and Youth Services Review. 2012; 34(6): 1121-1129.

57. Salazar AM, Keller TE, Gowen LK, et al. (2012). Trauma exposure and PTSD among older adolescents in foster care. Social Psychiatry and Psychiatric Epidemiology. 2012; 48(4): 545-551.

This manuscript was published online December 12, 2014 in the Journal of Behavioral Health Services \& Research. The final publication is available at Springer via http://link.springer.com/article/10.1007/s11414-014-9451-6

This activity is supported by a grant funded by both the National Institute of Disability, Independent Living, and Rehabilitation Research, and the Center for Mental Health Services Substance Abuse and Mental Health Services Administration, United States Department of Health and Human Services (NIDILRR grant 90RT5030). NIDILRR is a Center within the Administration for Community Living (ACL). The content does not necessarily represent the policy of NIDILRR, ACL, HHS, and you should not assume endorsement by the Federal Government.

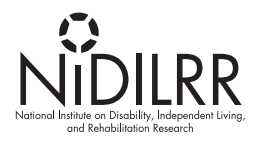
SAMHSA 